\title{
A LANÇA DE AQUILES E A OPINIÃO PÚBLICA NOS JORNAIS DO RIO DE JANEIRO (1875-1889)
}

\author{
George Vidipó ${ }^{1}$
}

Recebido em: 27/05/2020

Aprovado em: 27/07/2020

Resumo: O presente artigo investiga como o termo "opinião pública" era empregado nos jornais no último quartel do século XIX. Sua utilização era recorrente na imprensa do Rio de Janeiro, sendo importante como justificativa e autenticidade das críticas, defesas de eventos, na opção política e econômica. A metodologia utilizada nessa pesquisa é da "história dos conceitos", defendida por Koselleck, na qual define que o conceito reúne em si a diversidade da experiência histórica, assim como a soma das características objetivas teóricas. Usaremos o recorte temporal de 1875 a 1889. O primeiro ano marca o aparecimento do jornal Gazeta de Notícias, defensora da "imprensa neutra", a folha mais importante do último quartel do século XIX. O segundo ano marca a mudança da forma de governo do Brasil.

Palavras-chave: Opinião Pública; Imprensa Neutra; Imprensa Partidária, Imprensa Religiosa; Gazeta de Notícias.

\section{LA LANZA DE AQUILES Y LA OPINIÓN PÚBLICA EN LOS PERIÓDICOS DE RÍO DE JANEIRO (1875-1889)}

Resumen: Este artículo investiga cómo el término "opinión pública" fue utilizado en los periódicos en el último cuarto del siglo XIX. Su uso fue recurrente en la prensa de Río de Janeiro, siendo importante como justificación y autenticidad de las críticas, defensas de eventos, en la opción política y económica. La metodología utilizada en esta investigación es la "historia de conceptos", defendida por Koselleck, en la que define que el concepto reúne en sí la diversidad de la experiencia histórica, así como la suma de las características objetivas teóricas. Usaremos el marco de tiempo de 1875 a 1889. El primer año marca la aparición del periódico gazeta de notícias, defensor de la "prensa neutra", la hoja más importante del último cuarto del siglo XIX. El segundo año marca el cambio en el camino del gobierno en Brasil.

Palabras clave: Opinión pública; Prensa Neutra; Prensa de Partido, Prensa Religiosa; Gazeta de Notícias.

\footnotetext{
${ }^{1}$ Professor de História do Ensino Médio da Secretaria de Estadual de Educação do Rio de Janeiro, Mestre em História pela Universidade Salgado de Oliveira (UNIVERSO). Membro da ALCAR (Associação Brasileira dos Pesquisadores de História da Mídia). E-mail: historiavidipo@ yahoo.com.br. ORCID: https://orcid.org/0000-00020798-1628.
} 


\section{THE SPEAR OF ACHILLES AND PUBLIC OPINION IN THE NEWSPAPERS OF RIO DE JANEIRO (1875-1889)}

Abstract: This article investigates how the term "public opinion" was used in newspapers in the last quarter of the 19th century. Its use was recurrent in the press of Rio de Janeiro, being important as justification and authenticity of criticisms, defenses of events, in the political and economic option. The methodology used in this research is the "history of concepts", defended by Koselleck, in which he defines that the concept brings together the diversity of historical experience, as well as the sum of theoretical objective characteristics. We will use the time frame from 1875 to 1889 . The first year marks the appearance of the Gazeta de Notícias newspaper, an advocate of the "neutral press", the most important leaf of the last quarter of the 19th century. The second year marks the change in the way of government in Brazil.

Keyword: Public Opinion; Neutral Press; Party Press, Religious Press; Gazeta de Notícias.

O presente trabalho, tem como base os estudos desenvolvidos por Marco Morel (2005) e Lúcia Bastos Pereira das Neves (2009), que estudaram a evolução da "opinião pública" em diferentes momentos da história brasileira. Morel desenvolveu suas observações das décadas de 1820 a 1840. Neves baseou na teoria da "história dos conceitos" e analisou o termo baseada em documentos do círculo político do Brasil Império.

Nossa pesquisa focará como o conceito "opinião pública" foi utilizado nos jornais do Rio de Janeiro, nas últimas décadas de 1880, e como estes, os escritores, jornalistas se apropriaram do termo e tornaram a imprensa uma autoridade, formadora e juíza da "opinião pública”.

Chamou-nos atenção que nesse período a “opinião pública” fazia parte da discussão da sociedade carioca. Em 1878, o jovem Arthur Azevedo, recém-chegado ao Rio de Janeiro, em colaboração com Lino Assunção, apresentou a revista $O$ Rio de Janeiro em 1877. Na peça, aparece o casal protagonista, Zé Povinho e Opinião, que visitava a cidade. Ali chegando, desencontraram-se, pois, a Política e o Boato aproveitaram para separar o casal. O marido foi seduzido pela Política e, através das informações equivocadas do Boato, a esposa foi levada cada vez mais longe. Por sua vez, a Opinião, não queria se separar do companheiro e o procurava, mas ele, enganado ou "mal informado", continua fugindo, sempre acompanhado da Política. Os autores, após indicarem encontros e desencontros, fazem o Zé Povinho concluir: “A Opinião nunca está com o Zé Povinho, que é o mesmo que dizer que o Zé Povinho não tem opinião". (AZEVEDO, [1878], p.11)

A pesquisadora Tatiana Oliveira Siciliano comenta que Azevedo e Assunção entendiam que a Política só legislava em benefício da elite e que não permitia ao povo (Zé Povinho) ter opinião. Para Siciliano, os dramaturgos não vislumbraram, naquele momento, a imprensa como 
mediadora entre a Opinião e o Zé Povinho (SICILIANO, 2014, p. 132). Entretanto, para nós é curiosa a figura do Boato e como agia no Rio de Janeiro e propagava seus feitos. Na leitura da peça, surgiu uma dúvida: seria o Boato a imprensa, ou parte dela? Ao fim deste artigo poderemos responder. No entanto, ele confessa para a "Opinião" que usava a "imprensa" para atingir e confundir a cidade do Rio de Janeiro (AZEVEDO, [1878], p. 22).

Usaremos o recorte temporal de 1875 a 1889. O início marca o aparecimento do jornal Gazeta de Notícias, a folha mais importante do último quartel do século XIX, e 1889, o ano da mudança da forma de governo do Brasil. Nossa pesquisa tem como base teórica a "história dos conceitos", defendida por Reinhart Koselleck (2006), que nos permitiu analisar a variação da utilização do termo "opinião pública” pela imprensa no período. O teórico alemão adverte-nos:

Todo conceito se prende a uma palavra, mas nem toda palavra é um conceito social e político. Conceitos sociais e políticos contêm uma exigência concreta de generalização, ao mesmo tempo em que são sempre polissêmicos. (KOSELLECK, 2006, p.108)

Nesse sentido, procuraremos observar as mudanças históricas que estão acontecendo no Império e, de certa forma, na Europa, que influenciaram a utilização do termo “opinião pública” nos periódicos do Rio de Janeiro. Koselleck nos ensina:

O conceito reúne em si a diversidade da experiência histórica, assim como a soma das características objetivas, teóricas e práticas em uma única circunstância, a qual pode ser dada como e realmente experimentada por meio desse mesmo conceito. (OP. CIT., p. 109)

No período estudado, os jornais de maior circulação se declaravam "imprensa neutra" e se contrapunham à “imprensa partidária”. (VIDIPÓ, 2019) Nossa investigação, assim, estudará esses dois tipos de jornais do Rio de Janeiro: Diário de Notícias (1868), A Reforma (1869), Diário de Notícias (1870)², Gazeta de Notícias (1875), Semana Ilustrada (1861), O Cruzeiro (1878), Gazeta da Tarde (1880), Diário de Notícias (1881) e O Paiz (1884), além do jornal religioso O Apóstolo (1866).

\section{Opinião pública nos jornais}

Essa pesquisa teve como referência inicial a Gazeta de Notícias, criada em 1875, que, com uma nova proposta editorial, rapidamente cresceu no gosto dos leitores cariocas e da província do Rio de Janeiro. Nos seus dez primeiros anos, passou de uma tiragem de 10 mil

\footnotetext{
${ }^{2}$ Gondin da Fonseca (1941) chama-nos a atenção que a repetição dos nomes não significava ser a mesma empresa, nem um relançamento, ou seja, eram os jornais novos.
} 
para 18 mil e, em 1888, alcançou 28 mil exemplares. O Jornal do Commercio, outro importante jornal da cidade, permaneceu no período com a produção diária de 12 mil.

Arthur Azevedo, em 1878, em sua revista “O Rio de Janeiro em 1877”, apresentou-nos os principais jornais daquele ano: Jornal do Commercio, A Reforma, Diário do Rio, Diário Popular (moribundo), Globo e Jornal da Tarde. A Gazeta de Notícias já aparecia como personagem de destaque. Em cena, os jornais perguntavam como ela estava e foi respondido: "Muito bem... Ultimamente então, tenho sido muito procurada por causa dos folhetins de costumes ... do França [Júnior]!” (AZEVEDO, [1878], p. 21) Os folhetins de escritores nacionais e estrangeiros eram o grande chamariz do periódico.

O termo “opinião pública” era muito utilizado. No período de 1875 a 1880, na Gazeta de Notícias, aparecem 330 vezes e há um crescimento entre os anos de 1881 a 1889 para 1151 anotações, demonstrando-nos a importância do termo para a empresa jornalística. Quando observamos os demais periódicos, encontramos a mesma perenidade, exceção para as 2000 vezes, no período de 1866 a 1889, do jornal O Apóstolo. Já, no O Paiz, entre 1884 e 1889, o termo apareceu 484 vezes.

Na Gazeta de Notícias, o termo “opinião pública”, nos primeiros anos, era uma entidade com sentimento, atitude e com tomada de decisões. Também era sinônimo para povo e população. Havia uma distinção na sua utilização, entre jornalistas nacionais e os estrangeiros (Agência de Notícias Havas). Os primeiros, o utilizavam como sentimento ou sentido e o segundo utilizava como povo, população e pessoas. Vejamos esse exemplo da Questão Religiosa (1872-1875): "Se pode isentar-se da responsabilidade legal [Dom Pedro II], nem por isso se liberta da responsabilidade moral. Neste caso fica sujeito infalivelmente à sanção inexorável da opinião pública” (GAZETA DE NOTÍCIAS, 30 de setembro de 1875, p. 2).

Tal divisão era recorrente nos demais jornais: "Seja assim, mas enquanto não perdermos a fé na sabedoria do monarca e na força da opinião pública, tão solene e unanimemente manifestada”. (DIÁRIO DE NOTÍCIAS, 21 de maio de 1872, p. 1.)

Já no periódico $O$ Apóstolo, constatamos a apropriação do termo em seus argumentos, exposições de ideias, defesas de causas e da fé católica. Na sua pregação evangelística, o termo já estava inserido, como na parábola do "Administrador infiel” (Lucas 16:1-9): "Ei-lo [Administrador] convicto de caluniador, difamado pela a opinião pública e incurso na pena a que as leis o condenam". (O APÓSTOLO, 15 de julho de 1866, p. 1.)

O periódico também a utilizava para defesa dos interesses da religião e da igreja no Brasil ou no Europa: 
Notícias de Roma. (...) Cadorna, comandante das tropas invasoras, vê-se em talas para ter mão da gentalha que consigo trouxe a fim de fingir uma certa corrente de opinião pública em favor de anexação. Foi sem dúvida essa súcia [matilha] que correu as urnas, e deu em resultado esse tão famoso plebiscito,... (O APÓSTOLO, 13 de novembro de 1879, p. 6)

Nesse trecho, podemos observar que a "opinião pública" foi enganada e, por isso ela escolheu que os Estados do Vaticano fossem anexados ao Reino da Itália. Pela proposição, havia uma soberania do povo (opinião pública) para escolher, mas este fora "enganado". Para o jornal, prevalecia a vontade da Igreja sobre a opinião dos outros, ou melhor da "opinião pública”, mesmo que manifestada em um plebiscito.

O jornal também insere a “opinião pública” em momentos anteriores à criação do termo, no início da Idade Moderna. Observe:

Hoje a opinião pública é indulgente para com a heresia, por esta razão o crime de heresia foi riscado da lei penal. Mas, na Idade Média, o rigor de lei era exigido pela opinião pública... (O APÓSTOLO, 27 de novembro de 1873, p. $6)$.

Parece-nos que a "opinião pública” foi que exigiu que a Igreja criasse a Inquisição e não o inverso. Assim, para o jornal, as leis do Estado eram reflexos dela. O artigo do jornal não busca explicar por que ou como a "opinião pública" mudou de posição, ao longo dos anos.

Quando na década de 1880 aumentou a imigração europeia e com ela a entrada de europeus protestantes no Brasil, o Estado Imperial, então, preocupou-se em mudar a legislação para adaptar-se a nova composição da sociedade. Temas como liberdade de culto, casamento civil, cemitério público passaram a ser demandados no Parlamento e nos jornais. Desta forma, o periódico religioso se tornou um forte opositor a essas pretensões de mudanças. No Apóstolo, a retórica de condenação dessas necessidades legais teve como base a "opinião pública", que lhe dava peso e autoridade para criticar e condenar:

A opinião pública se levanta contra o mais nefasto projeto que se tem apresentado contra a religião católica, o que significa que este projeto não é uma necessidade, e muito menos uma aspiração do povo (O APÓSTOLO, 18 de novembro de 1888 , p. 2.)

Os jornais partidários (VIDIPÓ, 2019), em suas linhas políticas, utilizavam a "opinião pública" para fortalecer sua argumentação e defesa dos seus governos e, quando na oposição, na condenação deles. Em A Reforma, jornal do Partido Liberal, podemos ver: "O desprezo da opinião pública é o sintoma infalível de uma profunda perversão moral [do governo do Partido Conservador do Barão do Rio Branco]” (A REFORMA, 14 de fevereiro de 1871, p. 1).

A Gazeta de Notícias, imprensa neutra, em 1878, já havia percebido que todos falavam em nome da opinião pública: “Os liberais estão no governo, julgam ter por si a opinião pública; 
os conservadores de seu lado assoalham que a opinião é deles... Entre uns e outros, Sua Majestade se mantém silencioso...” (GAZETA DE NOTÍCIAS, 4 de agosto de 1878, p. 1.)

Os "jornais neutros", como a Gazeta de Notícias, em sua pretensa proposta de "neutralidade", também utilizavam o termo "opinião pública" como base de suas críticas ou de apoio as decisões dos governos. Na década de 1870 e, sobretudo na posterior, os periódicos utilizavam a "opinião pública" na justificativa e na autoridade de seus argumentos. Também observamos que o público-leitor, as empresas e as instituições passaram a utilizá-lo para defesa, venda de produtos, ataques, apoio, indicação a cargos etc. $\mathrm{O}$ termo também era utilizado como pseudônimo em eleições, acusação, vendas:

Veio a Opinião Pública tomar as dores pelo Sr. Dr. Pereira Passos. É o mesmo singular que a opinião pública, que tantas vezes têm aclamado contra o $\mathrm{Sr}$. Diretor, seja a mesma que agora toma a sua defesa. Coisas do mundo. (GAZETA DE NOTÍCIAS, 4 de agosto de 1878, p. 1).

Homens ilustres da sociedade imperial, que se achavam injustiçados ou que se colocavam como opção para um cargo na máquina governamental, utilizavam o termo nas folhas dos jornais para alcançarem seus objetivos: "Um jovem professor da escola politécnica, Dr. Antônio José Sampaio... resolveu apelar para o governo e para a opinião pública" (O PAIZ, 22 maio 1886, p. 3).

Os jornais passaram a ser reconhecidos ou se intitularem como "órgãos" da opinião pública. Esse termo, não foi explicado no período pesquisado pelos periódicos ou pelos jornalistas. A imprensa também era conhecida como aquela que "guiava" e "induzia" a "opinião pública". Isso não era inexpressivo ou condenado por ninguém, mesmo os políticos aceitavam esse poder de "guia". Para nós, de acordo com as fontes pesquisadas, a imprensa afirmava-se como a própria "opinião pública".

A “opinião pública” variava em sentido e aplicação nos periódicos, ora como sinônimo de grupo, ora sentimentos, ora como opinião. Os jornais utilizavam o termo como justificativa e balizadora de suas críticas, defesas, argumentos ou aprovações. Tais premissas eram autoimpostas, pois eles se declaravam "órgãos da opinião pública".

\section{A opinião era do povo ou do povinho?}

De acordo com o Dicionário Político de Bobbio (1998), o surgimento “opinião pública” coincide com a formação dos Estados Nacionais europeus e da sociedade civil dinâmica e articulada. Ela era formada por um segmento da população, certamente da burguesia, que não queria deixar sem controle a gestão dos interesses públicos nas mãos dos gestores dos Estados.

Outros pesquisadores da "opinião pública" apontam que o seu ponto de partida foi a Grécia Antiga (Atenas) e Roma, com as suas respectivas Ágora e o Fórum. Esses espaços eram instrumentos que "garantiam um fluxo informacional relevante até para darem conta das opiniões consensuais, 
antecipando-se as crises, o que, em alguma medida contribuía para fortalecer as ações tomadas pelos poderes político e militar." (FERREIRA, 2015, p. 56)

Tendo como referência essas civilizações podemos observar que parte da sociedade ficava fora das tomadas de decisões, nesse caso: escravos, estrangeiros e mulheres. Pode-se concluir que, ao longo da história, sempre algum grupo social ficava fora das disposições sobre o funcionamento de seus habitats.

No caso do Brasil do século XIX, a "opinião" e "informação" eram capitaneadas pela imprensa e, assim, era limitadas aos alfabetizados. A partir deles, os demais membros eram alcançados. Jürgen Habermas observa que esse processo era o mesmo na Europa. Assim ele nos indica:

...A opinião pública parte dos instruídos e difunde-se sobretudo entre aquelas classes que quando atuam em massa, adquirem preponderância. É certo que as classes populares mais baixas, os sans-culottes, não fazem parte disso, pois sob a pressão da carência e do trabalho não têm disposição nem oportunidade para se preocupar com coisas que não dizem respeito imediato às necessidades corpóreas. (HABERMAS, 2014, p. 262-263)

Azevedo e Assunção (1878) em sua peça, ao escolher o Zé Povinho, para tipificar a população da cidade do Rio de Janeiro demostrou que havia uma distinção na sociedade. Para nós, quando a imprensa utilizava o termo "opinião pública" como sinônimo de povo, esta não incluía a totalidade da população. Certamente "opinião" não era do Zé Povinho.

Desta forma é necessário saber o que o termo "opinião pública" significava para os brasileiros naquele momento. Para isso, utilizaremos os dicionários de português de 1728, 1789 e 1832. Segundo Lucia Bastos Pereira das Neves (2009) o termo só foi introduzido no final do século XIX, porém podemos estudar a evolução dos léxicos “opinião" e "pública”. Bem como, o léxico "povo", que tem uma variação de significados muito importantes para o entendimento do período estudado.

Raphael Bluteau (1728) define "opinião" como "o que se entende, se julga de alguma coisa, conforme notícias que se tem, ou se é um conceito, formam os homens em matérias não determinadas, ou se o afetam para uns, e não afetam averiguadas para todos". No final do século XVIII, Antonio Moraes Silva (1789) definiu “opinião” como "parecer, juízo que se forma de alguma coisa, voto que se dá, reputação, conceito bom", quanto ao verbo "opinar" é "dar o seu voto ou parecer, avaliar e reputar". Moraes Silva simplifica o termo, mas mantém a opinião como um julgamento.

Luiz da Silva Pinto (1832) afirma que "opinião" é "juízo que se faz de alguma coisa, reputação e presunção", no verbo "opinar" é o "mesmo que votar, dar seu parecer". Moraes Silva (1789) e Silva Pinto (1832) se aproximam na significação como "juízo de algo". No entanto, não identificam a sua origem. Bluteau (1728) avança nesse algo como "conforme 
notícias" ou esse juízo é de acordo com "alguma coisa" que é trazido para ser opinado ou que é exigido, ou seja, não é espontânea a opinião. Alguém ou algo tem que levar um assunto para que o opinador dê seu "parecer".

Vamos analisar como varia a significação de "pública". Para Bluteau (1728) é "comum, os cidadãos, a gente de qualquer lugar, o comum dos homens”. Antonio Moraes Silva (1789), mantém o significado "do comum, do uso de todos. O público, a gente de qualquer lugar". Para Silva Pinto (1832) "do comum, conhecido, usado por todos" e ao contrair a palavra em "O público, o povo, gente de qualquer terra”. Pinto, introduz uma nova associação, que os dois primeiros lexicógrafos do século XVIII não fizeram, "público” é igual a "povo". Essa palavra, nos vez continuar nossa investigação, Silva Pinto nos diz que "povo" é o mesmo que "moradores de uma cidade, nação" e no sentido figurado diz "o que tem costume e credulidade do povo" e define uma distinção em "povo miúdo" que é o mesmo que "plebe”. Bluteau (1728) identifica que o povo tem divisões "povo miúdo, a plebe, o vulgo, a gente baixa de qualquer povoação". Parece-nos que "povo" tem uma qualidade negativa em seu entendimento das coisas, diz ele "povo se chama que segue opinião ou as máximas do povo". Moraes Silva, utilizando aplicação do "povo" na literatura observa "é, do vulgo, e não sois capazes de entender o que o vulgo compreende". Com isso, ele mantém a distinção do "povo" e "povo miúdo" que era o mesmo que "plebe e gentalha". No período de 100 anos se manteve essa distinção e divisão. Podemos, assim, compreender que os teóricos do século XVIII, estavam presos a sociedade de ordem, mas o último, Moraes Silva, apesar de viver em um tempo de revolução social na Europa, manteve a significação.

Nessa pequena incursão na significação das palavras "opinião" e "pública", podemos associá-las em "opinião pública". Segundo os lexicógrafos, seria o mesmo que "julgamento de algo por todos" ou "voto comum" ou "parecer dos moradores da cidade ou da nação" ou "juízo de alguma coisa do povo". Parece-nos que o primeiro termo aceito com facilidade, mas o segundo nos leva a ter uma dúvida: qual povo? A “opinião pública” era do "povo" ou do "povo miúdo"? Qual opinião valia e era importante? Importante para quem?

Arthur Azevedo, como vimos, optou em apresentar como protagonista o "Zé-povinho", que era a representação que os literários do século XIX utilizavam para classificar "o povo miúdo". Esse personagem era afastado da "Opinião", devido as artimanhas da "Política" e do "Boato".

Na década de 1870, os jornalistas, os intelectuais e a elite político-econômica tinham o costume de classificar parte da população analfabeta, inculta e pobre de "raia miúda, plebe, povinho e Zé-povinho”. Maria Tereza Chaves de Mello nos dá uma importante contribuição: 
Em texto da época [1870-1889], republicanos ou não, há uma condescendência piedosa e mesmo admiração pelo "Zé Povinho", humilde, ignorante, ingênuo, mas trabalhador. (...) Mas capoeiras, prostitutas e afins continuavam a pertencer a uma ralé rejeitada, à categoria da desordem, que não constituía um atrativo para qual corrente política, (...). (MELLO, 2007, p. 204)

No jornal O Paiz, podemos ver como se diferenciava o povo: "Dizem que a Constituição garantiu ao povinho a posse do olho da rua, e que ele se acha em suas quintas quando faz reuniões ao ar livre, nos territórios alcunhados de logradouro público". (O PAIZ, 4 de agosto de 1887, p.1) Também era comum apontar que nas reuniões estavam presentes "todas as classes", com isso valorizar o "povo". Vejamos esse exemplo no Diário de Notícias quando foi declarada a libertação dos escravos no Município Neutro, Rio de Janeiro: "Exemplo estupendo da grande ideia que teve por operários todos os partidos, todas as classes, fundindo unicamente no sentido de pátria e humanidade". (DIÁRIO DE NOTÍCIAS, 9 de fevereiro de 1888, p. 2)

Os periódicos quando utilizavam o termo "opinião pública" utilizavam como sinônimo de um público letrado. Não era utilizado como referência as camadas mais simples ou os pobres da sociedade, pois elas os jornais tinham termos e adjetivos específicos.

\section{A imprensa como formadora ou a própria opinião pública}

Os periódicos tinham consciência que era "formadora da opinião pública", embora poucas vezes os jornalistas apresentassem essa alternativa. Entretanto, podemos ver um exemplo em um artigo de Ferreira de Araújo, redator-chefe da Gazeta de Notícias, na defesa da colonização europeia:

... Esses, cujo patriotismo não vai além do interesse tão bem dissimulado como mal entendidos são os que mais frequentemente repetem: - No Brasil, é privilégio do Rio Grande do Sul a produção de trigo. Assim se forma a opinião pública. (GAZETA DE NOTÍCIAS, 31 de janeiro de 1878, p. 1.)

Não era só a imprensa tinha essa pretensão, outras organizações também propunham a isso. A Sociedade Central de Imigração ${ }^{3}$, fundada em 1883, como resultado da negação da imigração de chineses para o Império, proposta de Lafayette Rodrigues, presidente do Conselho dos Ministros. Após impedi-la, a organização passou a defender a imigração de europeus e o seu assentamento em pequenas propriedades em todo o território nacional. Tinha como exemplo o "sucesso" e a política praticada nas províncias do Sul (MESQUITA, 2000). Em seu

\footnotetext{
3 Inicialmente tinha o nome de "Sociedade Brasileira de Imigração", posteriormente substituída por "Sociedade Central de Imigração".
} 
comunicado inicial, divulgado pela Gazeta de Notícias, observamos: “... formar a opinião pública e, por meio dela obter medidas legislativas, amplas e favoráveis ao engrandecimento real do Brasil, pela ação da imigração europeia, deve ser nosso empenho...” (GAZETA DE NOTÍCIAS, 17 de outubro de 1883, p. 2).

Tal objetivo foi alcançado, quando Dom Pedro II, em sua Fala do Trono de 1889, propôs a implantação de pequenas propriedades no Império, utilizando terras devolutas. Algo esquecido com a implantação da República alguns meses depois (VIDIPÓ, 2018).

Embora não tenha utilizado o termo "formar a opinião", o jornal $O$ Paiz, que se declarava "imprensa neutra", utilizou desse entendimento para propagar a mudança da forma de governo. Um exemplo de crítica ao governo do Gabinete, de 28 de Março, de José Antônio Saraiva:

Se o governo do Estado fosse, como presume tão reverente, tão solícito em atender as justas reclamações desse poderoso órgão do pensamento nacional. Se nas deliberações de ordem política e de ordem administrativa, os honrados ministros procurassem inspirar-se no conselho desinteressado e patriótico de nós outros que pretendemos ser os ministros permanentes da opinião pública e os arautos da vontade popular, os conselheiros arautos da vontade popular... (O PAIZ, 8 de dezembro de 1884, p. 1)

Vejamos na crítica a organização política "Não se renovando senão pela morte, aquela câmara [alta] está ainda menos sujeita aos corretivos salutares da opinião pública, do que os pareados aristocráticos, como da Inglaterra...”(O PAIZ, 22 de abril de 1885, p. 3).

Em poucos momentos, a imprensa era questionada como "órgão da opinião pública". $\mathrm{Na}$ verdade, os jornalistas que eram confrontados, já os jornais eram perdoados. Observemos esse exemplo na campanha pela "Libertação do Município Neutro" da escravidão:

... A imprensa, que se interessa pelo bem público, desligada de qualquer compromisso de conveniências de grupo, tem sempre estado à primeira linha dos soldados da liberdade. Tomando a peito a honrosa tarefa de libertar, dentro em breve prazo, o município da corte,... (O PAIZ, 22 de abril de 1885, p. 3)

... o ilustre deputado geral e provincial de São Paulo, o Sr. Nogueira: a opinião pública sempre vale alguma coisa, ... A imprensa não é tanto a opinião de meia dúzia de gazeteiros, como ilustre parlamentar apregoa; ela é uma força porque representa a vontade coletiva de muitos. (O PAIZ, 22 de abril de1885, p. 3).

O que era a opinião pública? Como se sabia o que ela queria? Como se chegava à opinião da maioria? Qual o tamanho da opinião pública? Como diferenciar a opinião do "gazeteiro" da opinião da maioria? Nos periódicos "neutros" ou "partidários" pouco se questionavam sobre essas indagações. Ficava claro que "as imprensas" sempre estavam com a maioria. 
Entretanto, como vimos acima, apareceram questionamentos a essa autoridade dos jornais. Na longa discussão das "Leis Abolicionistas" (1871-1888), os políticos se digladiavam e, com eles, os periódicos. Nessa luta, os abolicionistas se colocavam como representantes da “opinião pública”, mas não era possível dizer ou mensurar seu tamanho. Políticos recebiam representações, abaixo-assinados contra as leis abolicionistas.

O jornal $O$ Paiz, ao se defender do Deputado Nogueira, não explicou o tamanho do grupo que tinha aquela opinião pública e utilizou para isso: "[a imprensa] representa a vontade coletiva de muitos". (O PAIZ, 22 de abril de 1885, p. 3). O editorialista do O Paiz, então, apresenta seu poder de persuasão sobre a opinião pública:

Em todo caso, é bom que o ilustre parlamentar saiba que a imprensa vale, pelo menos, tanto como a tribuna; esta seria estéril, se não ecoassem no jornalismo as sublimidades e enormidades proferidas entre as quatro paredes de qualquer salão ou salinha... (O PAIZ, 11 de abril de 1886, p. 2)

Em nossa pequena pesquisa, somente no $O$ Apóstolo e na Semana Ilustrada surgiram questionamentos sobre a "opinião pública”. O Paiz, em 1888, comenta:

A opinião pública pode modificar-se, pode formar-se, pode reconstituir-se. As ideias novas podem ter livre curso, em todas as camadas sociais, germinar, (...) Tudo e todos podem caminhar, (...) segundo as circunstâncias. (O PAIZ, 15 de julho de 1888 , p. 2.)

Para o jornal O Paiz, a "opinião" era uma ideia que surgia e se modificava de acordo com as circunstâncias. No entanto, o jornalista não demonstrou como esta se modificava e nem quais os segmentos da sociedade que tinham poder para transformá-la. Porém, era com certeza a imprensa a justificadora e amplificadora dessas mudanças. Prevalecendo assim, a indicação que os periódicos, neutros ou partidários, eram os guias (NOVIDADES, 25 de janeiro de 1887, p. 1) ou mentores da "opinião".

Como vimos, Arthur Azevedo e Lino Assunção apresentaram como seus protagonistas Opinião e Zé Povinho. O antagonista, Boato, então, falou como agia no Rio de Janeiro para a Opinião: “- Estou em toda parte..., mas meu lugar predileto é na imprensa... imprimo um cunho especial a certas notícias". (AZEVEDO, [1878], p. 22) Os dramaturgos parecem-nos atestar que a imprensa e os jornalistas aceitavam que as notícias fossem divulgadas em suas folhas sem a devida verificação ou como a Semana Ilustrada denunciou por “20 vinténs a linha”. (SEMANA ILUSTRADA, 27 de outubro de 1861, p. 6).

O Apóstolo, em sua ação proselitista, usava a “opinião pública” para ter mais autoridade em caso de confronto com um inimigo momentâneo ou para reafirmar suas crenças. Temos aqui dois exemplos: 
Formada a opinião pública cumpre respeitá-la e o que aceitar. (...) E por isso que defendem de preferência seus interesses particulares, não podem ser considerados senão separados da opinião pública, única que pode e deve dirigir os negócios públicos em uma nação constitucional... (O APÓSTOLO, 30 de julho de 1871, p. 6)

$2^{\circ}$ - Contra a opinião pública: “... Não é lícito promover o juízo tribunal incompetente da opinião pública sobre estabelecimentos de que os bispos são os protetores e juízes naturais." (O APÓSTOLO, 22 de março de 1876, p. 3).

No primeiro caso, a "opinião pública” é sabia, tem que ser respeitada. Já no segundo, é “tola e incompetente". Será que são as mesmas "opiniões públicas"? O que mudou? Mudou, sim, a opinião do periódico sobre os assuntos expostos. Nesse sentido, os jornais, os outros “órgãos da opinião pública", são os deturpadores ou os maus formadores da "opinião pública". Vejamos um exemplo na "Unificação Italiana":

Bem se compreende a que se tende com tais invenções [conciliação entre o Rei Italiano e o Papa]; quer se desencaminhar a opinião pública, induzir em erro certos leitores, com cuja sinceridade contam justamente para os persuadirem, que os ânimos vão-se aproximando... (O APÓSTOLO, 29 de agosto de 1877, p. 1.).

Não sabemos o objetivo editorial da revista Semana Ilustrada, mas sabemos que ela estava inserida entre os mais prestigiados veículos da mídia impressa, no último quartel do século XIX. Já em 1861, observava a relação entre imprensa e opinião pública: “O jornalismo, órgão da opinião pública! Segue, mutatis mutantes a mesma norma de conduta. Defende os seus interesses e ataca os dos contrários, arvorando a opinião pública em "nariz de cera"”. (SEMANA ILUSTRADA, 27 de outubro de 1861, p. 6) "Nariz de cera", nesse momento, tem o sentido daquele que é levado por outro, que não tem opinião. $\mathrm{O}$ artigo continua, onde denuncia como a imprensa forma a opinião pública:

A opinião pública, quando acorda de manhã, tem sempre o cuidado de examinar os papagaios de papel que se distribuíram naquele dia, e, ao ver um deles gritar "escândalo"! "Corrupção"! "Imoralidade"! (...) a opinião pública quando acorda [no outro dia] dizia ou exclamava: Pois eu pensei ontem em tal?!" (OP. CIT.)

A revista Semana Ilustrada criticava a imprensa como “órgão da opinião pública”, pois os jornalistas recebiam, em sua maioria, "20 vinténs por linhas” para apoiar ou condenar o governo ou qualquer pessoa. Para Revista, a "opinião pública” era soberana, mas a imprensa sempre a levava para onde queria. Assim, sua desaprovação era pertinente contra os demais órgãos da imprensa, embora reconhecesse que também era um dos "órgãos da opinião pública".

Imprensa! O $5^{\circ}$ poder do Estado como lhe chamou um escritor; a instituição miraculosa que, à semelhança da lança de Aquiles, cura as feridas que faz; o veículo poderoso de transmissão do pensamento - o livro, o panfleto e o jornal (SEMANA ILUSTRADA, 14 de maio de 1871, p. 3) 
Nessa exposição, a Revista utiliza uma alegoria importante, a "lança de Aquiles", que curava ao defenestrar o golpe. Segundo a mitologia, ao ser retirada fechava a ferida. Entretanto tal feito só acontecia com a permissão do poderoso Aquiles. Assim, ele era a representação da imprensa, que, segundo a Semana Ilustrada, podia matar ou curar o ferimento, por ela criada, de acordo com sua vontade. Um poder inigualável da imprensa.

A Semana Ilustrada não sabia quantificar ou se era real a "opinião do públice” ou a origem da "opinião pública”: “...as gazetas de maior circulação, cada uma das quais se julga verdadeiro órgão da opinião pública, que ninguém sabe onde mora”. (SEMANA ILUSTRADA, 14 de maio de 1871, p. 3)

$O$ Apóstolo traz-nos mais sobre esse quantitativo da "opinião pública", em sua defesa dos ritos católicos ou da manutenção conservadora da sociedade imperial. No debate que se travou contra a adoção do casamento civil, cemitérios públicos e a liberdade de culto nos anos de 1888 e 1889, propostas por Visconde de Taunay e Silveira Martins no Parlamento. Eles, mais a Sociedade Central de Imigração, achavam que eram medidas essenciais para a modernização do Brasil e para maior atração de imigrantes europeus.

Taunay, em debate na tribuna do Parlamento e na imprensa, utilizava das representações e monções enviadas para ele para justificar o apoio da "opinião pública”. Já O Apóstolo, utilizava a mesma estratégia para justificar sua contrariedade sobre o projeto. Em 1888, o jornal confrontou o senador Taunay sobre qual era a verdadeira "opinião pública”, ou seja, qual era a maior opinião da população. Em novembro de 1888, o senador apresentou uma representação da Câmara de Manhuaçu, Minas Gerais, apoiando o casamento civil (GAZETA DE NOTÍCIAS, 27 de outubro de 1889, p. 1.). O Apóstolo, então, levantou uma representação contra, de 45 mil brasileiros, entre "senhores" e "senhoras" de várias partes do Brasil. O senador não reconheceu essa representação, justificando que a maioria das assinaturas era de meninas de colégios católicos, beatas e de pessoas que nem sabiam ler. O jornal então questionou: "Então 45 mil brasileiros não representam a opinião pública e cinco de Manhuaçu é que representa a aspiração nacional?" (O APÓSTOLO, 3 de novembro de 1889, p.3)

Em 1922, Walter Lippmann (2010), observando a imprensa americana do início do século XX, percebeu que era direcionadora, mesmo "apelando" para o público "em todo tipo de questões”. Sua crítica estava na incapacidade, ou capacidade inescrupulosa, dela apresentar a opinião de todos os lados sobre um evento, questão ou assunto. Assim, Lippmann conclui: "Pode haver vários outros lados, não mencionados por nenhum dos organizados, financiados e ativos militantes". (LIPPMANN, 2010, p. 336) 
Tal preocupação não é percebida nos periódicos no período estudado, prevalecendo a premissa de direcionar e guiar a opinião. O Zé Povinho e a Opinião sempre tiveram o Boato e a Imprensa os acompanhando e impedindo de ser um casal.

A opinião da população ou da sociedade era conhecida ou se fazia conhecer pelas representações ou por manifestações nas ruas. No entanto, era a imprensa a fiadora e como a "lança de Aquiles" dizia se era verdadeira ou não.

\section{Considerações finais}

Lúcia Bastos Pereira das Neves (2009) observou que o termo já era utilizado no Brasil desde 1808, com a inauguração da imprensa. No entanto, nos dicionários portugueses, não há nenhuma menção à "opinião pública”. O conceito só foi inserido em um dicionário português, no Brasil, em 1890 (NEVES, 2009, p. 195). Curiosamente, após a implantação da República.

A opinião pública nos periódicos era utilizada por jornalistas, intelectuais, pessoas comuns e entidades nos artigos e notas nos jornais como justificadora para críticas, apoio, solicitação, vendas, campanhas etc.. Ela tinha o sentido de pessoas, população, sentimentos. Entretanto observamos nos últimos anos da década de 1880, passou a ser empregada como opinião de um "público" ou do "povo". Sendo que esse público era certamente o alfabetizado e com boa formação sociocultural. A maioria da população que era analfabeta e pobre tinha sinônimos mais específicos: "povinhos", "arraia miúda” ou Zé Povinho".

A imprensa se autodenominava órgão da "opinião pública" e, em muitos momentos era a própria “opinião pública". Esse poder guiaria, direcionaria ou mudaria a "opinião" do públicoleitor.

\section{Fonte}

A REFORMA. Rio de Janeiro: A Reforma, 1869-1880.

DIÁRIO DE NOTÍCIAS. Rio de Janeiro: Diário de Notícias, 1868-1889.

GAZETA DE NOTÍCIAS. Rio de Janeiro: Gazeta de Notícias, 1875-1889.

NOVIDADES. Rio de Janeiro: Novidades, 1887-1889.

O APÓSTOLO. Rio de Janeiro: O Apóstolo, 1866-1888,

O PAIZ. Rio de Janeiro: O Paiz, 1884-1889.

SEMANA ILUSTRADA. Rio de Janeiro: Semana Ilustrada, 1861-1875. 


\section{Referências bibliográficas:}

AZEVEDO, Arthur. O Rio de janeiro em 1877. [s. l.] [1878] - Disponível em: http://objdigital.bn.br/Acervo_Digital/Livros_eletronicos/O\%20Rio\%20de\%20,Janeiro\%20e m\%201877.pdf - Acesso em: 29 de junho de 2018.

BLUTEAU, Rafael. Vocabulario portuguez, e latino, aulico, anatomico, architectonico, bellico, botanico ... : autorizado com exemplos dos melhores escritores portuguezes , e latinos; e offerecido a El Rey de Portugal D. Joaõ V. Coimbra, Collegio das Artes da Companhia de Jesu: Lisboa: Officina de Pascoal da Sylva, 1728.

BOBBIO, Norberto; MATTEUCCI, Nicola; GIANFRANCO, Pasquino (coord.). Dicionário de política I. Brasília: Editora Universidade de Brasília, 1998.

FERREIRA, Fernanda Vasques. Raízes históricas do conceito de opinião pública em comunicação. Belo Horizonte: Em Debate, v.7, n.1, 2015, p.50-68.

FONSECA, Gondin da. Biografia do jornalismo carioca (1808-1908). Rio de Janeiro: Livraria Quaresma, 1941.

GRINBERG, Keila; SALES, Ricardo (org.). Brasil Imperial, volume III (1870-1889). Rio de Janeiro: Civilização Brasileira, 2009.

HABERMAS, Jürgen. Mudança estrutural da esfera pública. São Paulo: Editora Unesp, 2014.

KOSELLECK, Reinart. Futuro Passado: Contribuição à semântica dos tempos históricos. Rio de Janeiro: Contraponto; Editora Puc-Rio, 2006.

LIPPMANN, Walter. Opinião Pública. Petrópolis: Vozes, 2009.

MCCOMBS, Maxwell. A Teoria da Agenda: a mídia e a opinião pública. Petrópolis: Vozes, 2010.

MOREL, Marco. As Transformações dos Espaços Públicos: imprensa, atores políticos e sociabilidades na cidade imperial (1820-1840). Rio de Janeiro: Editora Hucitec, 2005.

NEVES, Lucia M. Bastos Pereira das. Opinião Pública. In: FERES JÚNIOR, João. Léxico dos conceitos políticos do Brasil. Belo Horizonte: Editora UFMG, 2009, p. 181-202.

PINTO, Luís Maria da Silva. Diccionario da lingua brasileira. Ouro Preto: Typographia de Silva, 1832.

RIBEIRO, Lavina Madeira. Imprensa e espaço público: a instituição do jornalismo no Brasil 1808-1964. Rio de Janeiro: e-paper, 2004.

RODRIGO ALSINA, Miguel. A construção da notícia. Petrópolis: Vozes, 2009.

SICILIANO. Tatiana Oliveira. O Rio de Janeiro de Artur Azevedo: cenas de um teatro urbano. Rio de Janeiro: Mauad X; Faperj, 2014.

SILVA, Antonio de Moraes. Diccionario da lingua portugueza composto pelo padre D. Rafael Bluteau, reformado, e accrescentado por Antonio de Moraes Silva natural do Rio de Janeiro. Lisboa: Simão Tadeu Ferreira, MDCCLXXXIX [1789].

TRAQUINAS, Nelson. Teorias do Jornalismo: A tribo jornalística - uma comunidade interpretativa transnacional. Florianópolis: Insular, 2005.

VIDIPÓ, George. Burgos agrícolas e a pequena propriedade nos jornais do século XIX. In: SARMIENTO, Érica (coord.). E-Imigração em Debate: novas abordagens na contemporaneidade. Niterói: Associação Salgado de Oliveira de Educação e Cultura, 2018, p. 9-22.

VIDIPÓ, George. Imprensa neutra no século XIX: uma análise necessária. In: REGO, Ana Regina et. al. Os desafios da pesquisa histórica da comunicação: entre a historicidade e as lacunas da historiografia. Porta Alegre: Edipucrs, 2019, p. 355-378. 